\title{
El proceso de comprensión en el análisis de datos cualitativos en educación
}

Este artículo de reflexión se deriva de la investigación "El conocimiento profesional del profesorado universitario: procesos de construcción y transferencia a la práctica docente". Se plantea que, si bien existen diversos procedimientos para desarrollar el análisis de datos cualitativos en Educación, todavía conocemos poco acerca del proceso mediante el cual los investigadores asignan sentido a los datos y construyen sus conclusiones. Este trabajo pretende arrojar luz a ese proceso y mostrar el papel de las asunciones de trasfondo del investigador en dicho análisis. Con tal fin, en primer lugar, se describe cómo la noción de comprensión se ha construido en el campo de la Hermenéutica y luego se presentan sus implicaciones metodológicas.

doi: 10.11144/Javeriana.M7-14.EPCA

Escrito por José Luis Medina-Moya UNIVERSIDAD DE BARCELONA BARCELONA, España jlmedina@ub.edu

\section{Palabras clave descriptor}

Investigación sobre la educación, metodología, análisis cualitativo, comprensión.

\section{Transferencia a la práctica}

Al desvelar el rol de las categorías de trasfondo del investigador en el análisis de datos, este trabajo contribuirá a que este tome mayor conciencia de los procesos de selección, exclusión de episodios y de representación (de asignación de significado) mediante los cuales "construye" los resultados de su investigación. Hacer explícitos esos procesos proporciona un "contexto" para que el lector comprenda su informe de investigación y, además, al diferenciar los "datos" recogidos de los patrones que ha configurado con su interpretación para darles sentido, la comunidad de investigadores puede valorar la plausibilidad de tales interpretaciones.

Para citar este artículo / To cite this article / Pour citer cet article / Para citar este artigo

Medina-Moya, J. L. (2014). El proceso de comprensión en el análisis de datos cualitativos en educación. magis, Revista Internacional de Investigación en Educación, 7(14), 39-54. 
Key words plus

Research on Education, Methodology, Qualitative Analysis, Comprehension.

\section{Mots clés descripteur}

Recherche sur l'éducation, méthodologie, analyse qualitative, compréhension.

\section{Abstract}

There are various methods to carry out the analysis of qualitative data in education. But we still know little about the process by which researchers make sense of data and build their conclusions. This paper aims to shed light on this process by showing the role played by the background assumptions of the researcher in the process of analyzing qualitative data. To this end it is described, first, how the notion of comprehension has been built in the field of Hermeneutics and, then, its methodological implications for the analysis of qualitative data in education.

\section{Transference to practice}

This work, by revealing the role played by the background categories of the researcher in analyzing data, will help the researcher to be more conscious of the selection processes, exclusion of episodes, representation (meaning allocation) by which the researcher "builds" the results of his/her research. Making explicit these processes provide "a context" that make "intelligible" the research report. Also, to distinguish the collected "data" from the patterns that have been built by the interpretation of the researcher to give them sense, allows the community of researchers to value the plausibility of the interpretations that were made.

\section{Résumé}

Il y a divers procédures pour développer l'analyse de donnés qualitatives en éducation. Mais on connait encore peu sur les processus par lesquels les chercheurs donnent un sens aux donnés et façonnent leurs conclusions. Ce travail vise projeter une lumière à ce processus en montrant le rôle que les assomptions profondes du chercheur jouent dans le processus d'analyse des données qualitatives. Avec cet objectif on décrit, en premier lieu comment la notion de compréhension a été construite dans le domaine de I'herméneutique et après on montre les implications méthodologiques par rapport à l'analyse de données qualitatives en éducation.

\section{Transfert à la pratique}

Ce travail en montrant le rôle que les catégories profondes jouent dans l'analyse de données fait une contribution face au chercheur qui pourra prendre une plus haute conscience des processus de choix, exclusion d'évènements de représentation (d'assignation de signification) par lesquels on construit les résultats de la recherche. En faisant explicites ces processus on donne un contexte par lequel le lecteur puisse faire intelligible son bilan de recherche et, d'ailleurs en faisant la différence des données prises des modèles qu'il a construit avec son interprétation pour donner de sens permet à la communauté de chercheurs donner de l'importance à la plausibilité des interprétations réalisées.

\section{Palavras-chave descritor}

Pesquisa sobre a educação, metodologia, análise qualitativa, entendimento.

\section{Resumo}

Existem diversos procedimentos para desenvolver a análise de dados qualitativos em educação. No entanto, ainda conhecemos pouco a respeito do processo mediante o qual os pesquisadores atribuem um sentido aos dados e constroem suas conclusões. Este trabalho pretende iluminar esse processo mostrando o papel da profundidade do pesquisador no processo de análise de dados qualitativos. Com tal fim descreve-se, em primeiro lugar, como a noção de compreensão se construiu no campo da hermenêutica e, em seguida, se mostram seus envolvimentos metodológicos para a análise de dados qualitativos em educação.

\section{Transferência à prática}

Este trabalho, ao desvelar o papel das categorias de profundidade do pesquisador na análise de dados, contribuirá a que este tome maior consciência dos processos de seleção, exclusão de episódios, representação (atribuição de significado), mediante os quais "constrói" os resultados de sua pesquisa. Explicitar esses processos proporciona "contexto" para que o leitor possa tornar "inteligível" seu relatório de pesquisa e, além do mais, ao diferenciar os "dados" coletados dos padrões que construiu com sua interpretação para lhes dar sentido, permite à comunidade de pesquisadores avaliar a plausibilidade das interpretações realizadas. 


\section{Introducción}

La tradición de la investigación cualitativa, antes que uniforme, es una perspectiva en la que confluyen campos tan dispares como la Antropología, la Lingüística, la Hermenéutica, la Fenomenología o la Sociología y se desarrolla con una multitud de aproximaciones metodológicas como la etnografía (Woods, 1987), la etnometodología (Garfinkel, 1967), el interaccionismo simbólico (Blumer, 1969) o la teoría fundamentada (Glaser \& Strauss, 1967). En realidad, no existe un canon normalizado para el desarrollo de una investigación cualitativa.

Su gran diversidad metodológica no impide que todos esos enfoques compartan una serie de aspectos comunes acerca de la naturaleza de la realidad a la que se aproximan: el carácter interpretativo, holístico, dinámico y simbólico de todos los procesos sociales, incluidos los de investigación (Lowenberg, 1993); el contexto como origen y destino de los significados sociales (Erickson, 1989); el objeto de la investigación es la acción humana (por oposición a la conducta humana) y las causas de esas acciones que residen en el significado interpretado de las personas que las realizan, antes que en la similitud de conductas observadas (Mitchell \& Cody, 1993); la comprensión teleológica antes que la explicación causal como objeto de la construcción teórica (Von Wright, 1980) y la objetividad que se alcanza al acceder al significado subjetivo que la acción tiene para su protagonista (Morse, 1986). Es, sobre todo, la premisa del interés por el horizonte mental y práctico del sujeto social como territorio a explorar lo que late en el fondo de todos esos métodos.

Uno de los procedimientos básicos mediante los que se desarrolla esa exploración del mundo interior del sujeto y del significado que para él tienen sus propios actos y acciones es el Análisis de Datos Cualitativos (ADC). Este conjunto de procedimientos más o menos formalizado busca descifrar el sentido que habita en el corpus de datos, esto es, comprender la realidad analizada. Mas ¿cuál es el significado de esta noción de comprensión? ¿Qué papel desempeña en el proceso de ADC? ¿Cómo se decide la significación que se atribuirá a los datos? ¿Con qué criterio se determina que un dato es un indicador relevante de algo? ¿Cómo seleccionamos unos u otros epítetos para calificar el dato, habida cuenta de que esta operación no es posible sin elegir al mismo tiempo la clasificación que se va a utilizar? ¿Cuál es el rol de las asunciones de trasfondo del investigador?

En este trabajo intentaré mostrar las repercusiones de los diversos modos de aproximarse a los conceptos de interpretación, comprensión y apropiación en los procedimientos de análisis de datos cualitativos. Al revelar ciertos supuestos epistemológicos implícitos en las formas tradicionales de desarrollar el análisis de datos cualitativos, este trabajo intenta decir algo clarificador acerca de cómo conducirlo.

\section{El corpus de datos como "texto"}

Ricoeur (1999) sostiene que podemos denominar "texto" a todo discurso' fijado por la escritura. Así, el corpus de datos es la fijación del discurso que, en el contexto de la investigación cualitativa, se entiende
Descripción del artículo | Article description | Description de l'article Artigo descrição

En este artículo de reflexión, el autor aborda, en primer lugar, la noción de comprensión, como ha sido asumida en la Hermenéutica $y$, en segundo lugar, muestra sus implicaciones metodológicas para la investigación cualitativa en Educación, centrado en las que afectan los procesos de análisis de datos cualitativos. Este artículo se deriva de la investigación "El conocimiento profesional del profesorado universitario: procesos de construcción y transferencia a la práctica docente", código Plan nacional de I+D+I EDU-2008-05964-C03-01/EDUC, financiada por el Ministerio de Ciencia e Innovación de España.

1 La noción de discurso que utilizaré es subsidiaria del pensamiento de Foucault. Además de la dimensión semántica y lingüística de la comunicación, entiendo por discurso ciertas prácticas sociales que guardan una relación dialéctica con aquella, es decir, no solo aquellos significados transmitidos por el lenguaje, sino aquellas prácticas y procesos sociales que contribuyen a producir los significados y las subjetividades de quienes participan en ellos. El discurso se 
como las expresiones lingüísticas referidas al mundo de la vida de los actores sociales o como las acciones que los individuos realizan en ese mundo vital. Es usual que la constitución del corpus de datos sea posterior al acto de habla o a la acción que en él se recogen. Las transcripciones de, por ejemplo, observaciones o entrevistas suponen fijar, con un grafismo lineal, todas las expresiones discursivas previas durante el trabajo de campo: transcribir de forma directa "aquello que quiso decir el discurso".

Cuando los datos han sido consignados por escrito², en el momento de analizarlos, el investigador se convierte en "lector intérprete" y deja de actuar como interlocutor (en una entrevista) o como participante (en una actividad social más o menos institucionalizada), del mismo modo que ahora el texto ha sustituido al informante o a la acción. Aquí, la relación del investigador con el texto es distinta a la que mantenía con los participantes en la investigación durante el trabajo de campo; no es ya un diálogo vivo en el que existe un intercambio de preguntas y respuestas ni la participación más o menos activa en una acción social.

Ahora bien, ¿qué le sucede al enunciado una vez transcrito después de ser pronunciado? La transformación de la acción o del habla en texto, aunque sea una transcripción literal de palabras o actos, supone un cambio ostensible de la relación entre este y las subjetividades implicadas en él: la del investigador (ahora lector intérprete) y la de los autores del discurso (los sujetos investigados, ahora ausentes). Este cambio afecta a la relación referencial del lenguaje con el mundo de la vida. ¿Qué entendemos por función referencial? En el discurso, al dirigirse en palabra o acto a otro sujeto, el actor social "dice" algo sobre algo. Aquello sobre lo que habla o sobre lo que actúa es el referente de su discurso, pero es importante remarcar que, cuando el texto ha sustituido a la acción o al habla, esta función referencial se ve alterada (Ricoeur, 1986). En toda situación social mediada lingüísticamente (en una entrevista en profundidad, por ejemplo), los hablantes están presentes e interactúan en una situación y un contexto que es el entorno circunstancial de su discurso. Este discurso es significativo en relación con dicho contexto, pues remite a una realidad que puede ser mostrada y, en ocasiones, captada "alrededor" de los interactuantes. Desde luego, el lenguaje ordinario posee recursos suficientes para garantizar ese arraigo a lo real: demostrativos, pronombres personales o adverbios de tiempo y lugar permiten establecer ese vínculo. Así, en la praxis de la vida cotidiana, el significado ideal de lo que se dice se desplaza hacia la referencia real: hacia aquello de lo que se habla o hacia lo que se pretende con una acción cualquiera. En el discurso, esta referencia implica la acción de mostrar, de hacer ver. El significado se agota en la referencia y esta, en el acto de mostrar (Ricoeur, 1995).

Cuando el corpus de datos sustituye a la realidad de la que procede, esa que el investigador trata de comprender, ya no sucede lo mismo (Ricoeur, 1999). Ese desplazamiento hacia la acción de mostrar se ve interrumpido de manera parcial. Entonces, dice Ricoeur (1999), el texto se encuentra, en cierto modo, desconectado del mundo de la vida, en el aire. Si, durante una entrevista en profundidad, la intención comunicativa del hablante y el sentido del discurso se transponen de modo que es lo

refiere a lo que puede ser dicho y pensado, pero también a quién, cuándo y con qué autoridad puede hablar. Los discursos producen y transmiten significados, a la vez que implican un cierto tipo de relaciones sociales. Son prácticas institucionalizadas que configuran los objetos de los que hablan y constituyen sistemas de posibilidad de conocimiento.

2 Aunque en algunas investigaciones los datos y las evidencias se recogen con un soporte audiovisual, en su mayoría los datos textuales suelen conformar buena parte del corpus de datos. 
mismo comprender lo que el hablante quiere decir y lo que su discurso significa, ahora esa intención ha dejado de ser la voz de alguien presente que puede matizar nuestra apreciación de su querer decir. En el momento de la fijación del habla o de la acción en el corpus de datos se manifiesta, en toda su extensión, algo que sucede en ocasiones en las interacciones comunicativas de la vida cotidiana: cierto grado de separación entre el sentido y la ocurrencia del acto comunicativo que lo expresa (Habermas, 1982). Aunque el acontecimiento comunicativo es fugaz y volátil, su huella no desaparece por completo; algo puede quedar retenido en forma de significado en la mente del interlocutor que escucha. Lo que la transcripción de los datos fija y retiene no es el acontecimiento de habla (una entrevista, por ejemplo), sino lo "dicho" del habla. Ahora, el sentido verbal del texto no tiene por qué coincidir con el querer decir de su autor, o sea, el texto libera su sentido del tutelaje de la intención mental de quien los produjo y su referencia de los límites de la referencia situacional (Ricoeur, 1995).

Esta autonomización del texto respecto a sus relaciones con el mundo y con el intercambio de discursos, que en Derrida (1967) adquiere el carácter de independencia absoluta, es realizada por Ricoeur, con el fin de abrir la posibilidad de una "explicación" del texto que atienda a su estructura interna. Este "análisis estructural", que deberá ser elaborado por la lingüística, exige al lector que permanezca en "el lugar del texto", lo clausure y desarrolle una lectura carente de toda exterioridad, que no tiene por objeto nada que transcienda al texto.

Esta operación de suspensión transitoria de la relación única y directa del texto con el mundo de la vida del que procede, que Ricoeur (1999) hace para el caso de los textos que no son transcripciones de discursos, nos autoriza, con las debidas precauciones en el contexto del ADC, a relacionar con libertad el corpus de datos con todos aquellos otros textos que podrían vincularse con el contexto vital que es mostrado por el habla y la acción transcritas en el corpus de datos. Esta operación de "despsicologización" no implica la cancelación de toda referencia al "querer decir" del sujeto autorial. No se trata, dice Ricoeur (1995), de oponer una forma de interpretar el corpus basada en la categoría de acontecimiento de habla a otra, que sería su antagonista, fundada en el análisis estructural del contenido proposicional de los textos. Lo que nos permite esta operación de relativa autonomización del texto respecto a la intención autorial es ampliar el universo referencial del corpus de datos. Esta posibilidad es la que, a mi juicio, encierra potencialidades del ADC todavía por explorar.

El corpus de datos tendría dos referentes y no uno: un momento vital en el que habita un sentido emic (su horizonte interno) que debe ser captado por el investigador y el abanico potencial de significados a los que se refiere (su horizonte externo) y al que se puede apelar para desarrollar propuestas de interpretación no previstas en el sentido emic. Así, el sentido del corpus de datos queda librado del tutelaje exclusivo de la intención mental allí transcrita. Cuando el investigador aísla unidades de significado durante el $A D C$, podría considerarlas simultáneamente como unidades de un psiquismo ajeno susceptibles de ser re-vividas, como unidades de acción cuya intencionalidad puede ser captada y también como unidades cuyo significado potencial no se agota al vincularlas a lo que quiso decir o hacer el sujeto, es decir, el sentido de una oración puede ser tanto interno como externo a la oración a la que puede ser transferido.

Esta expansión también podría justificarse por la distinción que se encuentra tanto en Husserl (1949) como en Dilthey (1949) entre el significado de las palabras, las representaciones asociativas que despierta (Gadamer, 1977) y el contenido psíquico real de la conciencia. Para Husserl, 
el sentido de un enunciado es algo "ideal", pues no existe en la realidad social ni en la realidad psíquica: es pura unidad de sentido sin localización real. Dilthey (1949) distingue, como se mostrará más adelante, entre acto psíquico y significado lingüístico.

En el corpus de datos dejan de coincidir la intención del autor (informante) y el sentido verbal del texto. Entonces, la interpretación de los datos no se agota en la búsqueda de unidades de significados inmanentes al texto, un sentido pleno que pueda ser entendido, sino que es necesario, además, apelar a todos aquellos otros significados requeridos para que la comprensión acontezca. Esta ampliación del universo referencial del corpus de datos queda recogida en la distinción que Hirsh (1967) establece entre meaning (lo que el autor ha querido significar mediante una particular secuencia de palabras o acciones) y significance (la relación entre el querer decir del autor y el mundo de significados disponibles). Esta distinción sugiere que durante una entrevista en profundidad, por ejemplo, el entrevistado intenta sintonizar las palabras y oraciones que emite con aquello que desea decir, pero este ajuste no agota la integralidad del significado potencial de aquellas. Como recuerda Gadamer (1977), ninguna palabra tiene en sí misma el sentido que transmite, pues no existe una identidad incólume de los códigos. La significación verbal no es la significación completa. Ahora podemos completar la afirmación de Ricoeur (1995) que postula la existencia de un excedente de sentido que va más allá del signo lingüístico e incluso de la oración, originado tanto en el querer decir del entrevistado como en el universo de significados al que remiten sus palabras.

Gadamer (1977), por último, sostiene que, como el individuo no es capaz de abarcar todo, sus palabras, discursos o actos pueden significar algo que ellos mismos no tuvieron intención de mostrar y, por lo tanto, cuando se trata de comprender sus palabras o actos, puede pensarse, con razón, en cosas que a ellos no se les ocurrieron. Nos encontramos ante una cuestión de capital importancia en el análisis de datos cualitativos, que determinará la manera de conducirlo, relacionada con la forma de conceptualizar la noción de comprensión. Se refiere a la distinción entre una pretensión de verdad y una pretensión de sentido que puede o no ser una propuesta de verdad.

Gottob Frege (1973) tuvo el acierto de permitir que estas dos pretensiones cohabitaran en el interior del concepto de significado. Para Frege, toda expresión oral o escrita cuenta con dos rasgos semánticos diferentes: un sentido y un referente. El sentido, para Ricoeur (1995), es tanto aquello que el interlocutor pretendía decir, o sea, a lo que se refería (aquello que es dicho en el decir) como lo que significa la oración. El segundo componente del significado alude, para Frege, a la dimensión extralingüística del habla, expresa la propiedad referencial del lenguaje mediante la que el pensamiento se dirige por medio del sentido a entidades extralingüísticas como cosas, hechos, situaciones o acontecimientos del mundo. Es aquí donde se funda la pretensión de verdad de todo discurso. Existen expresiones cuyo referente es el mundo y cuya validez fáctica, su pretensión de verdad, puede ser contrastada y, quizá, demostrada; por ejemplo, el profesor alzó la voz para hacerse escuchar por encima del murmullo de los estudiantes. Aquí, sentido y verdad están muy próximos. Otras expresiones no tienen referentes fácticos para aquilatar su valor de verdad (por ejemplo, Pegaso y Poseidón se aliaron en su lucha contra la maldad de Policides), pero cualquier hablante comprende qué se quiere decir con esos términos. De este modo, esta oración tiene un significado, pues aunque no posea un referente empíricamente verificable, sí tiene un sentido. 
En síntesis, el investigador cualitativo puede considerar el corpus de datos como una huella del mundo vivido y, al tiempo, como un dato que va más allá de la intención de su autor y cuyos referentes, tanto empíricos como simbólicos, son los significados a los que pertenece (Marton, 1986). Si aceptamos que el corpus de datos es una instancia legítima de validación ha de considerarse que este cuenta con dos universos referenciales de los que obtiene su sentido y a los que apelaré para justificar una noción dual de la verdad, como correspondencia y como sentido, en relación con la cuestión de la validez o credibilidad del análisis de datos cualitativos.

EI ADC podría buscar en el corpus de datos las relaciones entre la constitución interna o inmanente del significado y las intenciones externas o transcendentales de la referencia (Ricoeur, 1995). Esta apertura de los referentes de un texto es la que ha legitimado la presencia de enfoques y disciplinas en el análisis de datos cualitativos que, como la Lingüística, el análisis narrativo o el análisis semiótico del discurso, completan las perspectivas más habituales de la Antropología o de la Sociología en este campo.

\section{La noción hermenéutica de la comprensión}

En este apartado plantearé las diferentes maneras de definir la comprensión y las implicaciones que se derivan de cada una de ellas para el análisis de datos cualitativos.

El lugar y la tradición en los que se ha formulado y desarrollado en sus múltiples nexos y pliegues la noción de compresión ha sido el del horizonte filosófico de la Hermenéutica y sus figuras centrales, Heidegger, Gadamer y Ricoeur. Esta tradición que se remonta al siglo XVIII, centrada en principio en la exégesis de textos sagrados y en la interpretación de textos literarios, tiene como hilos conductores en la noción de comprensión el estudio del comportamiento humano y la diferenciación radical entre los objetos y métodos de las Ciencias Humanas (y Sociales) y de las Ciencias Naturales (Giddens, 1976).

El discurso contemporáneo de la Hermenéutica es un campo complejo y plural que acoge en su seno diversas concepciones, a menudo opuestas, acerca de lo que significa interpretar y comprender. No todos los autores partícipes de esta corriente de pensamiento están de acuerdo con la recepción de Dilthey en la Hermenéutica gadameriana y algunos se han resistido al cambio que impuso la Ontología hermenéutica de Heiddeger. Cada una de estas posiciones, como iré mostrando, tiene implicaciones diferentes para el desarrollo de la recogida y el análisis de datos cualitativos.

\section{La Hermenéutica metodológica}

Suele atribuirse al teólogo alemán del siglo XIX, Friederich Schleiermacher, el paso de una Hermenéutica centrada en disciplinas particulares como la Teología o la Filología, cuyas reglas de exégesis son dictadas siempre por el objeto a interpretar, a un análisis que toma la actividad misma de la comprensión como problema (Gadamer, 1977). De este modo, la Hermenéutica da un salto que va de la interpretación y aclaración de determinados pasajes oscuros de textos religiosos o literaritos al intento de comprender de la génesis del proceso humano de entender. Su trabajo se orientó a fundamentar teóricamente los procedimientos que comparten teólogos y filólogos para hacer inteligible el proceso más originario de comprensión de las ideas. Schleiermacher buscaba la universalidad de la Hermenéutica, al margen de todo contenido, al homogeneizar el procedimiento que permite entender todo tipo de discurso, antiguo o moderno, oral o escrito. Esta universalidad es posible gracias a la ubicuidad del orden interpretativo, puesto que está presente tanto en el discurso como en el diálogo. Ya no interesa la interpretación gramatical de los distintos pasajes más importantes de una obra aislada sino captarla en su conjunto en relación genética con la motivación psicológica que anima al autor interpretado (Schleiermacher, 2000).

Para Schleiermacher, el discurso tiene dos referentes: la totalidad del lenguaje y la totalidad del pensamiento del autor. Así, el discurso que recoge el corpus de datos presupone, en primer lugar, un lenguaje dado, una comunidad lingüística sobre cuyo trasfondo se dibujan el enunciado y el texto particular y, en segundo lugar, presupone una intención de querer decir algo: un autor específico. Comprender el discurso fijado en el corpus pasa por articular esas dos dimensiones.

Además, Schleiermacher expande el objeto de la comprensión más allá del texto, que ahora incluye el diálogo o la conversación. De esta ampliación nace una de las aportaciones más relevantes de este autor a la noción de comprensión y que, mediante los primeros trabajos de Dilthey, se ha convertido hoy en un lugar común en la retórica del ADC. Se trata de la subordinación de la interpretación gramatical a la interpretación psicológica que busca, como condición de posibilidad de la comprensión misma, la individualidad del hablante, por medio del regreso al origen de sus ideas. Este desplazamiento responde a un fenómeno que acontece en todo diálogo. En efecto, igual que sucede cuando se interpreta el corpus de datos, el interlocutor en un diálogo no pretende descifrar el significado literal de las palabras en su sentido objetivo, sino que está atento a lo que quiso significar su emisor, 
captar su singularidad y hacer inteligible su modo de estar en el mundo.

Para Dilthey (1949), en la senda de Schleiermacher, la comprensión era entendida como el proceso por el cual, a partir del signo dado a los sentidos, el intérprete tiene acceso a la realidad psíquica que manifiesta el signo. Dilthey concibe la tarea de las Ciencias Humanas de manera análoga al proceso de interpretación textual: se trata de descifrar el significado correspondiente a determinados signos. Estos signos, a los que se debe dirigir la comprensión hermenéutica, quedan subsumidos en tres manifestaciones de la vida: las expresiones lingüísticas (el discurso que intenta significar algo), las acciones (que hacen inteligible un contenido psíquico) y las expresiones de las vivencias (manifestaciones no lingüísticas como las mímicas, fisiognómicas o gestuales).

La psicología comprensiva del primer Dilthey trata de remontar la exterioridad de las expresiones vitales hacia una interioridad que las concepciones positivistas habían descuidado. La tarea de la Hermenéutica no es explicar lo exterior en lo que la experiencia se expresa, sino, mediante su descripción-objetivación, comprender la interioridad de la que ha surgido. Comprender no es intuir, congeniar o aplicar un conjunto de reglas; es iniciar un proceso por el que se conoce el interior de una vida con la ayuda de los signos en los que se expresa.

En la parte final de su obra, Dilthey (2000) hace una autocrítica al papel central que hasta entonces había asignado a la experiencia interna del individuo y desplaza su interés hacia la intersubjetividad lingüísticamente mediada. A partir de una noción de comprensión como una suerte de empatía que garantizaría el acceso al psiquismo del otro, Dilthey, influido por la Fenomenología de Husserl, empieza a pensar que los fenómenos de la conciencia y el mundo interior psíquico del individuo son accesibles a la comprensión solo por medio de significados compartidos entre intersubjetividades y articulados de manera simbólica por el lenguaje. Lo que se comprende son las expresiones simbólicas y la experiencia interna del individuo pierde valor frente a la intersubjetividad. Este desplazamiento desde el interés por la descripción de los estados de conciencia del otro hacia los significados que articula lingüísticamente, léase desde la Psicología hacia la Hermenéutica, tiene lugar porque Dilthey, que sigue en esto a Husserl, piensa que, aunque los objetos de la Psicología - los fenómenos de la conciencia- están dados de forma directa e inmediata (por ejemplo, nuestros propios acontecimientos psíquicos), este ámbito está restringido por su alto grado de clausura. Encontramos la prueba de ello cuando nos damos cuenta de que tenemos la experiencia del otro en forma distinta a como tenemos la experiencia de nuestros estados psíquicos. Lo experimentado por una persona no puede ser transferido de manera íntegra, como por ósmosis, a otra persona. Ricoeur (1986) insiste en que un acontecimiento perteneciente al fluir de un pensamiento no puede ser transferido como tal a otro fluir de pensamiento. Lo que se transmite no es el acontecimiento como tal, sino su significado. Nos encontramos ahora ante la inversión de la relación de subordinación que Schleiermacher había efectuado entre la interpretación gramatical y la interpretación psicológica.

\section{Algunas repercusiones para el análisis de datos cualitativos}

¿Qué repercusiones pueden tener para el ADC las nociones de comprensión vista hasta aquí? En primer lugar, al tomar en cuenta las consideraciones de Schleiermacher, podríamos decir que, durante el proceso de análisis, el investigador deberá transportarse mentalmente al psiquismo del autor del habla o de la acción recogidas en el corpus de datos, imaginar el contexto y las circunstancias vitales que dieron origen a sus palabras o acciones y "re-vivir" la experiencia de vida del informante. Hay un desplazamiento al mundo psíquico y social emic del informante. El objeto del análisis no es la intelección de la literalidad de las palabras y su sentido objetivo, sino la individualidad del hablante o del autor. El ADC debería ayudar al investigador a recrear en su mente el mundo interior del otro $y$, aunque se lleve a cabo un análisis tanto semántico como psicológico, el énfasis se pone en acceder al proceso interno de confección de una idea o de una acción: comprender es reproducir el sentido de la vivencia que el hablante quiso designar con sus palabras. Así, la buena interpretación de un dato (un relato, una observación) sería la que el autor podría aprobar, dado el contexto.

El análisis de datos cualitativos presupone la inversión de un acto de habla: interpretar es una reconstrucción. El corpus de datos recoge una manifestación vital y genuina de su autor, cuyo análisis debe ser capaz de mostrar las peculiaridades de la intención que allí habita y su textura emocional. Esto significa que en el trabajo de recogida y análisis de datos no se llega a la comprensión mediante la saturación empírica o la redundancia histórica, sino a partir de un originario acto genético que recrea la situación revisada en el momento de comprenderla. Se trata, en suma, de un suceso de reproducción. Este acto de subordinación a la intención autorial o a los estados de conciencia del otro es el que Betti (1955) defendería más tarde como la clave de su hermenéutica objetiva.

Sin embargo - esta es una primera derivación al ADC del pensamiento de Dilthey-, esa equiparación no significa mera identificación: la descripción que 
hace el investigador es distinta y no reemplaza a la experiencia descrita. La relación entre su explicación y lo explicado no es de identidad, sino generativa (Maturana, 1995). Esto quiere decir que la reconstrucción del proceso de producción de significaciones que hace el investigador durante el análisis le permitiría, eventualmente, comprender al autor mejor de lo que él mismo se habría comprendido. Esto es así porque el análisis permite hacer conscientes algunas cuestiones que pueden haber quedado en el inconsciente del autor. El investigador que estudia unas prácticas sociales en parte desconocidas y extrañas deberá adquirir conciencia expresa de las reglas implícitas que las regulan y que los actores sociales aplican de manera tácita, porque viven ese contexto con una "actitud natural" (Husserl, 1949).

Esta comprensión más sofisticada que podría desarrollar el investigador respecto a la realidad que estudia no se refiere a la comprensión de las cosas de las que se habla en el corpus de datos (a su valor de verdad), sino a lo que el autor tuvo en mente y a lo que expresó. Esta interpretación no trata de desentrañar la cosa a la que se refiera el texto; alude más bien a su sentido al margen de sus pretensiones de verdad. Esta distinción entre pretensión de sentido y pretensión de verdad, que aquí no desarrollaré por razones de espacio, late en el fondo de la concepción dual de la verdad que aparece en la hermenéutica existencial que se abordará más adelante.

Además de acometer la descripción psicológica de estados mentales de conciencia, otra función del ADC es captar el significado del corpus articulado lingüísticamente. Es importante anotar que, para Dilthey, el significado no es un concepto lógico, sino la expresión de una manifestación de la vida. Con Husserl, Dilthey distingue entre el acto psíquico de la conciencia y su contenido, entre la apercepción psíquica y su significado lingüístico. La comprensión a la que aspira el ADC no es, en exclusiva, una categoría exclusivamente psicológica, pues también es semántica. El ADC debe rescatar, entonces, la individualidad del sentido que habita en el otro, entendida ahora como una categoría intersubjetiva que ya no se genera en la mirada del investigador dirigida hacia el mundo interior del otro para describir sus estados mentales, sino en el espacio social de encuentro con los otros que está mediado lingüísticamente. El análisis debe abrirse a la interioridad del otro, pero solo podrá hacerla inteligible mediante una expresión o un significado lingüístico. Nos damos cuenta de que, al atender a la imposibilidad de transferir una conciencia como tal a otra conciencia a la que antes me refería, el sentido mental no puede encontrarse en ningún otro lado más que en el discurso mismo. Ese sentido inscrito en el querer decir del interlocutor deja su marca en el texto del corpus de datos (Ricoeur, 1995). Así, la finalidad del ADC es comprender la interioridad de otra persona en virtud de un signo fijado en el corpus; sin embargo, el investigador no debe perder de vista el excedente de sentido que rebasa las posibilidades semánticas del signo o de la oración al que antes se aludía.

En suma, el $A D C$ puede entenderse hasta aquí como la búsqueda en el corpus de datos de sentidos cuyos referentes serán tanto el mundo psíquico y lingüístico de los informantes, su querer decir, como el universo de significados posibles al que remite ese modo de estar en el mundo.

\section{Hermenéutica existencial y Hermenéutica objetiva}

Lo común a Schleiermacher y Dilthey es lo que de Heiddeger y Gadamer se resistirían a aceptar. Para ellos, la Hermenéutica, más que un método es el medio para comprendernos y conocernos existencialmente como seres humanos. 
En Heidegger, la Hermenéutica se radicaliza, pues ya no se pregunta por un modo de conocer por básico que este sea; comprender es ahora un "modo de existir" (Heidegger, 1962), el modo de ser de quien existe comprendiendo. Se sustituye así una analítica de la conciencia por una analítica de la existencia. Comprender no es dotar de inteligibilidad a la cosa, sino comportarse en el mundo. Heidegger no entiende, al modo de Dilthey, la Hermenéutica como la disciplina de la interpretación de los textos, preocupada por describir un proceso especial o método desarrollado por determinadas disciplinas científicas. No le preocupa fundamentar la comprensión de un determinado tipo de conocimiento o de ciencias (del espíritu en Dilthey); más bien, se dirige a clarificar la estructura de la precomprensión y de la comprensión de la existencia humana. Se trata de entender que la interpretación y la comprensión son constitutivas del ser humano, un componente central de su existencia, sin la que esta no puede ocurrir:

Al interpretar no arrojamos, por así decirlo, una interpretación sobre una cosa desnuda que está ante nosotros, no le asignamos un valor, sino que cuando algo de dentro-del mundo aparece como tal, la cosa en cuestión ya tiene una implicación tal que se revela en nuestro entendimiento del mundo, y esta implicación es tal que se proyecta en la interpretación (Heiddeger, 1962, p. 109).

El objeto de la Hermenéutica es el ser humano que existe interpretándose. Es una condición necesaria de su estar en el mundo. Sin embargo, aunque Heiddeger no estuviera interesado en la interpretación y comprensión de los textos escritos, hizo una importante contribución por su depurado y lúcido análisis de estos fenómenos y que, sin duda, ayudan a la intelección del proceso de dar sentidos a los datos procedentes del trabajo de campo.

Gadamer (1977), en la línea de Heiddeger, más que como un comportamiento metodológico respecto a un objeto dado, entiende la comprensión como lo que le pertenece al ser de lo que comprende. La Hermenéutica gadameriana, todavía inspirada en las Ciencias Humanas, renuncia a toda ambición metodológica. Comprender no es una actividad en la que los humanos se embarcan en ocasiones, cuando se aproximan a fenómenos como textos literarios o históricos; comprender es el modo básico de existencia del ser humano y ser humano es estructurar el mundo en términos de significado. Nuestra capacidad de comprender no se restringe a los textos; la capacidad de comprender a los otros se deriva de nuestra actividad más básica, la de interpretar el mundo. Para Gadamer (1977), toda comprensión es, en última instancia, un comprenderse. La comprensión se refiere tanto a la captación inmediata de lo que significa la expresión o el discurso como también al descubrimiento de la interioridad oculta.

En Gadamer como en Schleiermacher, la comprensión es el resultado del círculo hermenéutico: se produce como consecuencia de un vaivén entre las preconcepciones del intérprete - a las que Gadamer Ilamaría "prejuicios" mirada-y el texto a interpretar. En el proceso de comprensión se fusionan el horizonte del intérprete y los sentidos depositados en el texto.

3 Para Gadamer, son anticipos de nuestra apertura al mundo, condiciones para que podamos percibir algo, para que el texto "nos diga algo". Es un preentendimiento que posibilita cualquier acto interpretativo que, a la vez, le impone límites. 
Para Gadamer (1977), la comprensión es entender con otros (consenso intersubjetivo), referirse al unísono a las mismas cosas. Sin embargo, cuando el acuerdo desaparece o el consenso tácito se distorsiona, la comprensión se convierte en una tarea de la Hermenéutica. La idea, la conceptualización y la creencia ya no es la propia: es la del otro (o la del texto). Por ello, el objetivo último del trabajo hermenéutico, su verdadero problema, se manifiesta cuando, en nuestro intento por comprender a otro o a un texto, nos planteamos la cuestión de cómo ha llegado a construir o conformar su visión, conceptualización o creencia.

Uno de los autores que con más solidez ha tratado de continuar la senda trazada por Dilthey ha sido Emilio Betti. Pese a su notable contribución a la Hermenéutica moderna, contenida en su Teoria generale della interpretazione, su trabajo es poco conocido más allá de los círculos especializados. Este jurista italiano, con una sólida formación filosófica, propondría las bases para una metodología hermenéutica, científica y objetiva alejada de los planteamientos existencialistas de Heiddeger y Gadamer.

La obra de Betti posee aspectos de máxima relevancia para el proceso de investigación cualitativa, en general y para los procesos de análisis de datos y de construcción conceptual, en particular. La razón estriba en su interés por resolver el problema estrictamente epistemológico del comprender.

Para Betti (1955), la universalidad de la Hermenéutica radica en que cualquier actividad interpretativa, incluidos el Derecho, la Filología y la Historia, comportan una estructura epistemológica común. El papel de su hermenéutica general es definir las condiciones de una interpretación objetiva. Betti (1955) cree que cualquier proceso humano de interpretación es solo de naturaleza cognitiva y, por eso, se enfoca en resolver el problema epistemológico de la comprensión. En franca oposición a Gadamer, en la Teoría generale della interpretazione encontramos una clara reivindicación del alcance metódico de la Hermenéutica en contra de su ontologización existencial (Ferraris, 2000).

El método hermenéutico debe permitir el acceso al sentido objetivo depositado en el texto (una reconstrucción de sus determinaciones originarias) y no conferir un sentido que procede de la subjetividad del intérprete. Así, la buena interpretación y su validez residen en la exactitud con la que se capta y reconstruye la intención del autor.

Con esa finalidad en mente, Betti propone cuatro cánones, de los cuales Gadamer se interesa por los tres primeros, pues, además de asegurar la objetividad de la interpretación, permiten su verificación. Estas cuatro reglas las deduce de la dicotomía sujeto-objeto, que para él está en la base de todo conocimiento y que Gadamer niega con su noción de fusión de horizontes.
La interpretación objetiva resuelve esta disyunción al responder a una doble exigencia de objetividad y subjetividad mediante el cumplimento de cuatro puntos, de los cuales los dos primeros se relacionan con el sujeto y los dos últimos con el objeto. El canon de la autonomía del objeto impone al intérprete extraer el sentido de su interpretación de la intención autorial y no desde fuera de ella. El canon de la totalidad y la coherencia exige que el objeto sea interpretado como un todo en el que sus partes se hacen inteligibles recíprocamente; la coherencia es la del objeto y no la de la interpretación, puesto que esta es un mero reflejo de aquella. Estos dos cánones exigen la subordinación de la interpretación al sentido inmanente al objeto. El tercero, el de la actualidad, de manera semejante a lo que plantea Schleiermacher, propone que el intérprete debe recrear y recorrer en el interior de sí mismo de modo inverso el proceso genético que dio lugar al punto de vista del objeto. El cuarto canon, el de la correspondencia, exige al intérprete que adecúe y sintonice su interpretación con el mensaje que proviene del texto.

\section{Otras derivaciones para el análisis de datos cualitativos}

¿Qué otras derivaciones para el ADC podemos extraer, además de las propuestas por la Hermenéutica clásica, de la Hermenéutica existencial de Gadamer y de la Hermenéutica objetiva de Betti? Veámoslo con algo de detalle.

A la luz de la Hermenéutica de Gadamer, dar significación a los datos que contiene el corpus o el proceso mediante el que el investigador "sabe" consiste en integrar el texto en sus horizontes de inteligibilidad. Este proceso es bidireccional y dialéctico. Betti, de acuerdo con Gadamer, indica que elaborar significaciones por medio de la interpretación de datos es un proceso de "inversión interpretativa" que solo puede cumplir con la exigencia de subordinación a la intención autorial y actúa desde la propia subjetividad del intérprete. Se establece, así, un diálogo entre la esfera que incluye el texto a interpretar (según su propia autonomía intencional y semántica) y la esfera que pertenece a las categorías de significado del intérprete (según su viva actualidad).

En palabras de Gadamer (1977):

La persona que trata de comprender un texto realiza siempre un acto de proyección. Proyecta ante sí un significado del texto en su conjunto en el momento en el que surge del mismo algún significado inicial. Este último solo surge porque aquella lo lee con determinadas expectativas en relación con cierto significado. El resultado del anteproyecto, constantemente 
revisado en términos de lo que emerge a medida que penetra el significado, es la comprensión de lo que allí existe (p. 335).

Este es un proceso en realidad circular que Schleiermacher denominó círculo hermenéutico: un vaivén que podría desglosarse, solo a efectos didácticos, del siguiente modo: el investigador se acerca al corpus de datos con algunas presuposiciones y conjeturas sobre los significados que allí habitan; tiene preguntas por responder y un conocimiento más o menos elaborado sobre la realidad que desea conocer ${ }^{4}$. Durante el análisis, el investigador trata de "encajar" el texto en su horizonte de significados; en otras palabras, intenta acoplar sus conjeturas de sentido al querer decir del texto. La interpretación se inicia siempre con conceptos previos que deben ser sustituidos progresivamente por otros más adecuados. Este proceso de continuo vaivén del reproyectar no deja incólumes las presuposiciones del investigador.

Al principio, el investigador "vagabundea" por el territorio semántico del corpus con una serie de presuposiciones que, a modo de mapas heurísticos diferentes o de hipótesis de comprensión, rivalizan por imponerse. Hablar de "hipótesis de comprensión" significa que esas asunciones de trasfondo que ya tiene el investigador (y que lo poseen a él) cuando entran en relación con el corpus de datos lo hacen con una función "exploratoria". En algún momento será consciente de que una parte del corpus "significa algo", porque algunos de esos conceptos previos "sintonizan", de algún modo, con alguna parte del querer decir del texto. El investigador empieza a darse cuenta de que existe una determinada "similitud" entre sus categorías de sentido y los datos, sin que, en principio, pueda explicar en qué son similares o diferentes. En estos primeros compases titubeantes y exploratorios de ese proceso de "fusión de horizontes" que culminará con la comprensión del texto, ambas perspectivas cohabitan todavía de manera yuxtapuesta sin penetrarse. Por esta razón, el investigador "ve" el fragmento del corpus, cuyo "sentido" empieza a devenir como similar y como diferente a las cosas que ya conoce. Nótese que estamos hablando de un proceso de amalgamiento de perspectivas. Dentro de la variedad de hipótesis de comprensión que puedan tener un sentido para el investigador, no todo es posible ni pertinente. Esto significa que el investigador irá confirmando sus anticipaciones con el material de análisis y las

4 Se encuentra aquí la monumental y radical aportación de Heidegger a la Hermenéutica, que consisten en invertir la relación (secuencia) entre interpretación y comprensión: la interpretación se basa en la comprensión previa (precomprensión) y no al contrario. adecuará a su querer decir. Ese es el trabajo constante de la comprensión y parte de su rendimiento final, "lo que importa es mantener la mirada atenta a la cosa aún a través de todas las desviaciones a las que se ve sometido el intérprete en virtud de sus propias ocurrencias" (Gadamer, 1977, p. 333).

Sin embargo, no siempre los momentos iniciales del análisis son de este modo. También puede aparecer el fracaso. Si el investigador falla en el intento de acoplar las proyecciones exploratorias de su encuadre al texto, el insight de la comprensión no aparece en su conciencia y el texto permanece sin significado para él: no le dice nada, ve las palabras, pero no sabe cómo tomarlas. En este momento debe examinar sus suposiciones y "dejarse tocar" por el texto para modificarlas mediante una operación de parcial subordinación al querer decir del texto. Para ello, la curiosidad desempeña un papel destacado: preguntarse cómo el otro ha llegado a conformar "ese" punto de vista puede ayudar al investigador a desatascar el flujo del proceso de comprensión. Esto es lo mismo que Betti quiere decir cuando manifiesta que la comprensión surge si - y solo si- se ha sintonizado con la mente del autor. Se trata de apreciar cosas en el corpus de datos que van más allá de las apreciaciones iniciales del investigador y que cambian su concepción acerca de la naturaleza de las cuestiones que han de ser exploradas; "el que quiere comprender un texto tiene que estar en principio dispuesto a dejarse decir algo por él" (Gadamer, 1977, p. 335).

En ocasiones puede suceder que el éxito de esa "reintegración" en los marcos preexistentes del investigador sea parcial y tomará conciencia de que su intento ha fallado en parte. Este fracaso manifiesta la resistencia del querer decir del texto a subsumirse a plenitud en su marco previo, correlativa a la incapacidad de ese marco para captar lo que allí existe:

El que quiere comprender no puede entregarse desde el principio al azar de sus propias opiniones previas e ignorar obstinadamente la opinión del texto... hasta que este finalmente ya no pueda ser ignorado y dé al traste con su supuesta comprensión (Gadamer, 1977, p. 335).

Metodológicamente hablando, esto significa que la voz del otro no puede ni debe subordinarse al patrón de interpretación que el investigador esté aplicando, es decir, aunque el investigador interpreta el corpus de datos aportando sus asunciones de trasfondo al material, no alcanza su comprensión si no adecúa sus apreciaciones para captar la alteridad que allí habita. La relación del investigador con el corpus es transaccional: "elaborar las proyecciones correctas y adecuadas a las cosas, que como proyectos son 
anticipaciones que deben confirmarse 'en el texto', tal es la tarea constante de la comprensión" (Gadamer, 1977, p. 333).

Esto tampoco se consigue, dice Gadamer, con una autocancelación de las presuposiciones de trasfondo, sino que incluye una matizada incorporación de aquellas a la cosa que se comprende. Esta postura es del todo razonable, puesto que es imposible hacer abstracción de nuestras categorías de inteligibilidad cuando estamos interpretando.

Betti da algunas indicaciones sobre la dificultad de esa incorporación que no pueden obviarse si lo que se pretende es una hermenéutica rigurosa. Su postura también es del todo razonable: concebir la interpretación como un proceso en el que las categorías del intérprete se "incorporan" a la cosa que se comprende como condición necesaria para que el texto "le sea comprensible". ¿No puede transformar el análisis de datos en un monólogo? ¿Puede la interpretación constituir un verdadero diálogo si la irreductible intención autorial no puede hablar más que por mí? ¿No es el discurso del otro el que yo le impongo? ¿Cómo verificar la adecuación de las anticipaciones y proyecciones a la intención autorial? En suma, para Betti, la minusvaloración de la intención autorial en la Hermenéutica gadameriana supone la exclusión del significado, que es, en última instancia, la finalidad de la interpretación. Esta crítica del subjetivismo de la Hermenéutica existencial como criterio desorientador la plantea Hirsch (1967) de modo convincente:

Una vez que al autor se le privó despiadadamente de la prerrogativa de determinar el significado de su texto, se hace cada vez más evidente que no había ningún principio adecuado para juzgar la validez de una interpretación. Por necesidad intrínseca, el estudio de "lo que dice un texto" se convierte en el estudio de lo que el estudio le dice al crítico individual. Está de moda hablar de "la lectura" de un texto por parte de tal o cual crítico, y esa palabra empezó a aparecer en los títulos de obras científicas. Esto parecía implicar que si se había desterrado al autor, siempre quedaba el crítico, y su nueva, original, refinada, ingeniosa o pertinente "lectura" tenía su interés específico (p. 13).

Esta apreciación es razonable. Para Gadamer, la Hermenéutica no es un método y tampoco se orienta a la elaboración de interpretaciones "correctas" en función de lo que el autor quiso decir. El significado de un texto no reside en la intención autorial (de suyo inaccesible), sino en el resultado de la mediación entre el texto y quienes lo interpretan. Esta es una tarea infinita, pues aparecen nuevos significados en las "lecturas" dentro de nuevos horizontes de los intérpretes. Lo atractivo de esta propuesta es tan obvio como su problema. Al proponer la comprensión como una actividad que no se subordina a criterio alguno de exactitud con la intención del autor, la discriminación valorativa entre dos interpretaciones rivales se nos presenta como algo arbitrario.

Ante este problema, Betti sostiene que el pensamiento ajeno debe someterse a un proceso de apropiación (distinto al que ofrece Gadamer como "fusión de horizontes") que lo mantiene como "algo distinto" en su objetividad y alteridad. Con su canon de la totalidad, Betti propone que el sentido debe ser extraído del texto, sin disolver, como hace Gadamer, la distinción sujeto-objeto y no impuesto desde una alteridad. No obstante, en el lugar en el que nos deja Betti encontramos algunas cuestiones no resueltas: ¿Puede el investigador "apropiarse" de lo que le es extraño? ¿La alteridad asimilada por la subjetividad del investigador permanece intacta o deja de ser diferente? Y, en todo caso, ¿cuándo y cómo podemos saber 
que la "intención autorial", como ha sido reconstruida, corresponde a la intención autorial misma?

En suma, la discrepancia entre Gadamer y Betti se enfoca en el papel más o menos activo que la subjetividad del intérprete desempeña en el momento del análisis: Gadamer reivindica la tradición como condición necesaria del entender y Betti desea reducirla a su mínima expresión para que no ponga en riesgo la objetividad de la interpretación. El tercer canon de Betti, el de la actualidad, está pensado contra los caprichos de un subjetivismo absoluto. La subjetividad de Betti no es la del prejuicio gadameriano o la de la comprensión heideggeriana. Ambas implican la disolución de la distinción sujeto-objeto, que es refutada por Hirsch (1967), quien ve en la gadameriana fusión de horizontes un error categorial, al no distinguir en el corpus de datos un horizonte "interno" —el del texto, primario- de un horizonte "externo" - el del intérprete, secundario-. Ambos están presentes en la interpretación y la comprensión de un corpus de datos, pero con un valor diferente. El primero es inmanente al texto y hacia él debe dirigirse el esfuerzo interpretativo. El segundo, más amplio y menos importante, ya no pertenece al texto, sino al intérprete Esta distinción se basa en la diferenciación ya comentada entre meaning (el querer decir del autor) y signficance (cualquier otro vínculo que pueda establecerse entre ese querer decir y los significados disponibles para el intérprete).

A la vista de estas interesantes cuestiones que nos llevan a extremar la prudencia en el ADC, así como de los riesgos existentes, creo que es importante no olvidar el énfasis de Betti en tratar de reflejar con la máxima exactitud la intención autorial, sin renunciar a lo que nos ofrece Gadamer.

Es cierto que el corpus de datos es una "transcripción" de un querer decir. Así, la autonomía del texto respecto a su autor a la que se aludía es escasa. La falacia del texto absoluto que hace del corpus una entidad clausurada y sin referente alguno olvida que esos datos son, en realidad, la transcripción de un discurso narrado por alguien, para alguien y acerca de algo. Es imposible eliminar esta propiedad referencial fundamental del discurso sin expulsarlo de lo humano. Todo texto "refiere" una intención, ya sea de manera ostensiva, descriptiva o figurativa, pero también es verdad que no podemos concebir el corpus de datos como la fijación de un entramado de intenciones sin interrogarnos por el complejo proceso mediacional por el cual accedemos a ellas. El análisis de datos debería ser realizado de modo que facilite alcanzar una cierta correspondencia entre el sentido que habita en el corpus del texto y el convencimiento subjetivo del investigador $y$, al mismo tiempo, garantizar la máxima exactitud de ese proceso de comprensión: garantizar una máxima adecuación al significado depositado en el corpus sin obviar el rol de las precomprensiones del investigador.

Parece apropiado reclamar esa vigilancia epistemológica que proponían Bourdieu, Chamboredon y Passeron (1975), que aparece en esta edición especial en el texto de Guzmán, por la que el investigador se hace cargo de sus propias anticipaciones, con el fin de que el texto pueda presentarse en su alteridad. Esta apertura supone, por supuesto, poner la "voz" del texto en algún tipo de relación con las categorías de significado del investigador (Gadamer, 1977). Hacerse cargo y controlar las asunciones de trasfondo de nuestras propias anticipaciones también quiere decir que el investigador debe tomar conciencia de que el material del corpus que encaja en sus categorías (esa es la razón de su elocuencia) se convierte en figura de campo y oscurece detalles que pueden habitar en el corpus, pero que no están contemplados en aquellas. Se trata de una cuestión en la que se combinan, de manera indisoluble, la lucidez con la honestidad 
intelectual: un estar atento para no ser autorreferente y escuchar la voz de los autores, sin asumir la actitud de confirmación de las propias percepciones, las creencias y los sentimientos.

\section{El análisis como apropiación}

Como he venido argumentando, la comprensión del sentido que habita en el corpus de datos empieza con las proyecciones conjeturales mediante las cuales el investigador se enfrenta al querer decir del texto. Esa comprensión será completa (que no definitiva) cuando el investigador se ha "apropiado" del texto.

Las ideas explícitas o implícitas que el corpus de datos nos ofrece no podrían ser consideradas como algo con sentido si no fueran leídas por un ser que pueda hacerlas suyas. Esto es lo que quiere ponerse de relieve con el concepto de apropiación, que es fundamental en la Hermenéutica existencial. Subraya este concepto que el trabajo de análisis que nos lleva a la comprensión no acaba cuando se ha captado "la cosa del texto", sino cuando resulta, el algún sentido, aplicable al mundo del investigador que lo actualiza y hace propio, con lo que incide en la comprensión de sí (Gadamer, 1977).

La apropiación del material significa hacer explícitas las anticipaciones de sentido latentes en el acto de interpretar los datos y que actúan en el proceso de comprensión de manera decisiva, mas esta apropiación implica que lo inédito que se comprende resulta incorporado. Ahora bien, ¿qué significa hacer propio? En primer lugar, transformar en consciente o explícito lo que antes era tácito o desconocido. Aquello que era esquivo cuando las anticipaciones de sentido del investigador fracasaban, ahora no es ajeno, sino algo de él mismo, pues el análisis consiste en una interpenetración entre sus prejuicios (en el sentido gadameriano) y los plexos de sentido que residen en el material de análisis. Es importante remarcar que en este tránsito de lo implícito a lo explícito, además de constatar la existencia de un significado hasta ahora no revelado, aparece un cambio de la relación del investigador consigo mismo: esa revelación es un proceso de comprender-se. Tal proceso de explicitación no se hace en un vacío: cuando captamos un significado lo hacemos porque nuestras asunciones de fondo (léase precromprensiones) están actuando sobre el corpus de datos y anticipa su sentido; solo tenemos noticia de nuestros prejuicios cuando chocan con el material de análisis. Así, el corpus de datos que es afrontado con las presuposiciones de trasfondo del investigador se integra (o no) en su estructura mental, lo que, como he dicho, no la deja intacta. Esta reestructuración de sí mismo mediante la interpretación del material de análisis es una evidencia de que la comprensión no se agota cuando se ha captado "algún sentido" en el material, sino cuando este resulta aplicable al mundo del investigador que lo hace propio, al modificar su comprensión de sí. Nótese, por último, que esta apropiación no es un efecto colateral del análisis de un texto; más bien, como la ontología hermenéutica de Heidegger ha mostrado, es una consecuencia lógica del proceso de comprensión: la aparición del sentido en el texto y la constitución de sí son simultáneas en el análisis de datos cualitativos.

\section{Sobre la validez del análisis}

He afirmado que el proceso de precomprensióninterpretación-comprensión finaliza cuando el investigador siente que se ha apropiado del corpus de datos. ¿Es este el criterio de una interpretación exitosa? Si la interpretación que deviene en apropiación, según Gadamer en oposición a Betti, no es invertir de manera mecánica y aséptica la cadena de significados inscritos en el corpus de datos, sino retomarlos desde las anticipaciones de sentido del investigador que los revisten de un haz de nuevas posibilidades de comprensión; si la interpretación es, por tanto, un acto de creación como resultado inevitable de las posibilidades que proyecta el investigador cuyos horizontes de sentido no son meros estereotipos sociales, entonces la validez de la interpretación no puede medirse con estándares externos a sus marcos de interpretación. Si la validez de la interpretación se asienta en exclusiva en la experiencia del investigador de haber entendido el corpus de datos, ¿cómo decidimos entre dos interpretaciones rivales? Pese a ello, no todas las interpretaciones de una misma unidad de significado son equivalentes en términos de plausibilidad o pertinencia. ¿Cómo podemos establecer la distinción?

La solución a este problema que encontramos en la Hermenéutica existencial de Heiddeger y Gadamer es la siguiente: la Hermenéutica filosófica se interesa por el clásico problema de la verdad sin necesidad de plantearse el problema de su fundamentación. Postula una noción integral de verdad que no resulte prisionera de las pasiones modernas por las certezas o de los silencios posmodernos ante la evidencia (Domingo, 2013). La Hermenéutica operará aquí una extensión del significado de la noción de verdad desde las relaciones entre enunciados y hechos y entre enunciados mismos, hasta la aparición originaria del mundo como horizonte de sentido. Fue Heidegger quien sacó a relucir que la distinción sujeto-objeto solo es posible después de una constitución previa de sentido que los engloba a los dos y sin las que su relación no sería posible. Es esta pertenencia del sujeto a un ámbito más originario la que hace estéril tanto la pretensión de omnipotencia representacional de la subjetivad —que 
es todo menos un comienzo absoluto- como la idea de verdad, entendida como correspondencia entre un enunciado y un hecho previo, desnudo de toda anticipación de sentido.

En síntesis, la especificidad del discurso hermenéutico estriba en que no puede dejar de aceptar esta concepción dual de la verdad: como adecuación al objeto y como pertenencia a un ámbito de sentido existente antes de que la interpretación y la comprensión se pongan en marcha. Ricoeur (1999) trata de englobar estas dos dimensiones de la verdad cuando afirma que lo que "se ha hecho propio" no es solo algo mental o la intención del otro, sino la propuesta de un modo de ser en el mundo que el texto abre al investigador por medio de sus referencias no ostensibles.

\section{Sobre el autor}

José Luis Medina-Moya es doctor en Filosofía y Ciencias de la Educación. Se desempeña como profesor titular de la Facultad de Pedagogía de la Universidad de Barcelona.

\section{Referencias}

Betti, E. (1955). Teoria generale della interpretazione. Milán: Giuffrè.

Blumer, H. (1969). Symbolic Interactionism: Perspective and Method. Englewood Cliffs: Prentice-Hall.

Bourdieu, P., Chamboredon, J. C., \& Passeron, J. C. (1975). El oficio de sociólogo: presupuestos metodológicos. México D. F.: Siglo XXI.

Derrida, J. (1967). De la gramatología. México D. F.: Siglo XXI.

Dilthey, W. (1949). Introducción a las ciencias del espíritu: en la que se trata de fundamentar el estudio de la sociedad y de la historia (2a ed.). México D. F.: FCE.

Dilthey, W. (2000). Dos escritos sobre Hermenéutica: el surgimiento de la Hermenéutica y los esbozos para una crítica de la razón histórica. Madrid: Istmo.

Domingo, A. (2013). El arte de cuidar: atender, dialogar y responder. Madrid: Rialp.

Erickson, F. (1989). Métodos cualitativos de investigación sobre la enseñanza. En Wittrok, M. (coord.). La investigación de la enseñanza II. Métodos cualitativos y de observación. Barcelona: Paidós.

Ferraris, M. (2000). Historia de la Hermenéutica. Madrid: Akal.
Frege, G. (1973). Sobre el sentido y la referencia. En Moro, T. Semántica filosófica: problemas y discusiones. Buenos Aires: Siglo XXI.

Gadamer, H. (1977). Verdad y método. Salamanca: Sígueme.

Garfinkel, H. (1967). Studies in Ethnomethodology. Englewood Cliffs: Prentice-Hall.

Giddens, A. (1976). New Rules of Sociological Method. A Positive Critique of Interpretative Sociologies. Londres: Hutchinson.

Glaser, B., \& Strauss, A. (1967). The Discovery of Grounded Theory. Chicago: Aldine.

Habermas, J. (1982). Conocimiento e interés. Madrid: Taurus.

Heidegger, M. (1962). El ser y el tiempo (2a ed.). México D. F.: FCE.

Hirsch, E. D. (1967). Validity in Interpretation. New Haven: Yale University Press.

Husserl, E. (1949). Ideas relativas a una Fenomenología pura y una Filosofía fenomenológica. México D. F.: FCE.

Lowenberg, J. (1993). Interpretive Research Methodology: Broadening the Dialogue. Advances in Nursing Science, 16(2), 57-69.

Marton, F. (1986). Phenomenography. A Research Approach to Investigating Different Understandings of Reality. Journal of Thought, 21(3), 2849.

Maturana, H. (1995). La realidad: ¿Objetiva o construida? Barcelona: Anthropos.

Mitchell, G., \& Cody, W. (1993). The Role of Theory in Qualitative Research. Nursing Science Quarterly, 6(4), 170-178.

Morse, J. (1986). Quantitative and Qualitative Research: Issues in Sampling. En Chinn, P. (ed.). Nursing Research Methodology: Issues and Implementation. Rockville: Aspen.

Ricoeur, P. (1986). Del texto a la acción. Ensayos de Hermenéutica II. México D. F.: FCE.

Ricoeur, P. (1995). Teoría de la interpretación. Discurso y excedente de sentido. Madrid: Siglo XXI.

Ricoeur, P. (1999). Historia y narratividad. Barcelona: Paidós.

Schleiermacher, F. (2000). Sobre los diferentes métodos de traducir. Madrid: Gredos.

Von Wright, G. (1980). Explicación y comprensión. Madrid: Alianza.

Woods, P. (1987). La escuela por dentro. La etnografía en la investigación educativa. Barcelona: Paidós. 